\title{
Effects of EPA, $\gamma$-linolenic acid or coenzyme Q10 on serum prostate-specific antigen levels: a randomised, double-blind trial
}

\author{
Mohammad Reza Safarinejad*, Nayyer Shafiei and Shiva Safarinejad $\dagger$ \\ Clinical Center for Urological Disease Diagnosis and Private Clinic Specialized in Urological and Andrological Genetics, \\ PO Box 19395-1849, Tebran, Iran
}

(Submitted 21 May 2012 - Final revision received 20 September 2012 - Accepted 20 September 2012 - First published online 30 November 2012)

\begin{abstract}
The main objective of the present study was to determine the potential of $n-3$ and $n-6$ fatty acids or coenzyme $\mathrm{Q}_{10}$ (CoQ $\mathrm{Q}_{10}$ ) to alter serum prostate-specific antigen (PSA) levels in normal healthy men. A total of 504 healthy men with serum PSA level $\leq 2.5 \mathrm{ng} / \mathrm{ml}$ were recruited into the study. Serum PSA values were not segregated by decade of age. Participants were randomly assigned to a daily dietary supplement containing $n$ - 3 fatty acids ( $1 \cdot 12 \mathrm{~g}$ of EPA and $0 \cdot 72 \mathrm{~g}$ of DHA per capsule) (group 1, $n$ 126), $n$-6 fatty acid (600 mg $\gamma$-linolenic acid (GLA) each capsule) (group 2, $n$ 126), $\mathrm{CoQ}_{10}(100 \mathrm{mg}$ per capsule) (group 3, $n$ 126) or a similar regimen of placebo (group $4, n 126)$ for $12 \mathrm{weeks}$. Study medication was administered as two capsules to be taken twice daily. Serum levels of PSA, EPA, DHA, GLA, lipid profile and reproductive hormones were also measured. EPA treatment significantly reduced serum PSA level by $30 \cdot 0$ (95\% CI 25, 36) \% (P=0.004) from baseline. In contrast, GLA therapy significantly increased serum PSA concentration by $15 \cdot 0$ (95\% CI 11, 20) \% (P=0.02). CoQ 10 therapy also significantly reduced serum PSA level by $33.0(95 \% \mathrm{CI} 27,40) \%(P=0 \cdot 002)$. In multivariable analysis, serum values of PSA were strongly correlated with duration of EPA $(r-0 \cdot 62 ; 95 \% \mathrm{CI}-0 \cdot 42,-0 \cdot 77 ; P=0 \cdot 003), n-6(r 0 \cdot 42 ; 95 \% \mathrm{CI} 0 \cdot 31,0 \cdot 58 ; P=0 \cdot 02)$ and CoQ 10 use $(r-0 \cdot 77 ; 95 \% \mathrm{CI}-0 \cdot 56$, $-0.87 ; P=0.001)$. There were also significant correlations between serum values of DHA, EPA, GLA and CoQ 10 and serum PSA levels. The present study demonstrates that dietary supplements containing EPA, GLA or CoQ ${ }_{10}$ may significantly affect serum PSA levels.
\end{abstract}

Key words: Prostate-specific antigen: Measurement: $n$-3 Fatty acids: $n-6$ Fatty acids: Coenzyme $\mathbf{Q}_{10}$ : Prostate cancer

Prostate cancer (PCa) accounts for $28 \%$ of total cancer incidence $^{(1)}$ and is the second most common cause of cancerrelated death of men in the $\mathrm{USA}^{(2)}$. Prostate-specific antigen (PSA) testing is widely used for the detection of asymptomatic and early-stage $\mathrm{PCa}^{(3)}$. There is great controversy surrounding PSA screening, because a considerable number of men with elevated serum PSA, who were referred for biopsy, were not diagnosed with $\mathrm{PCa}^{(4)}$. Indeed, serum PSA concentrations may be affected by many factors unrelated to prostate disease, including age ${ }^{(5)}$, race ${ }^{(6)}$, type 2 diabetes mellitus ${ }^{(7)}$, dietary factors $^{(8)}$, certain clinical cardiac problems ${ }^{(9)}$ and obesity ${ }^{(10)}$. Consumption of some medications such as non-steroidal antiinflammatory drugs, acetaminophen ${ }^{(11)}$ and statins ${ }^{(12)}$ can also affect serum PSA levels. In general, overall PCa mortality is high in Northern Europe and North America, and is low in Japan and other Asian nations ${ }^{(13)}$. But, for Japanese migrants to the USA, the incidence of mortality increases as a function of the number of years lived in the USA ${ }^{(14)}$. The major contributory factor thought to account for this increased frequency in PCa death is the Western diet ${ }^{(15)}$. The fatty acid composition of Western diets has changed dramatically during the 20th century. Typically, the Western diet includes less n-3 PUFA and more $n-6 \mathrm{PUFA}^{(16)}$. Currently, the $n-6: n-3$ ratio in Western diets is approximately $15^{(17)}$. This ratio in the Japanese diet is $4: 1^{(18)}$. DHA, EPA and $\alpha$-linolenic acid are the main $n$ - 3 PUFA. Linoleic acid, $\gamma$-linolenic acid (GLA) and arachidonic acid are the main n-6 PUFA. Several investigations have reported the influence of PUFA on the development of PCa. $n$-3 PUFA inhibit human prostate cancer cell lines ${ }^{(19)}$, while $n-6$ PUFA increase the growth of human prostate tumour cell lines ${ }^{(19,20)}$. Akinsete et $a l^{(21)}$ reported that the administration of a high amount of $n$-3 slows down prostate tumorigenesis in mice. Kelavkar et $a l .{ }^{(22)}$ investigated the effects of the $n-6: n-3$ ratio in the diet on prostate tumour growth and recurrence. They concluded that the $n$-3 fatty acid stearidonic acid (precursor of EPA) induces apoptosis and declines proliferation in cancer cells, causing diminished PSA doubling time. Kobayashi et al. ${ }^{(23)}$ examined whether altering the dietary content of $n-3$ and $n-6$ PUFA affects the growth of androgen-sensitive PCa xenografts. They found decreased serum PSA in the $n-3$ diet group.

\footnotetext{
Abbreviations: $\mathrm{COQ}_{10}$, coenzyme $\mathrm{Q}_{10} ; \mathrm{DHT}$, dihydrotestosterone; GLA, $\boldsymbol{\gamma}$-linolenic acid; LH, luteinising hormone; PCa, prostate cancer; PSA, prostate-specific antigen; SHBG, sex hormone binding globulin.
}

*Corresponding author: M. R. Safarinejad, fax +98 21 22456845, email info@safarinejad.com

†The authors dedicate this paper to the memory of Shiva Safarinejad. 
Coenzyme $\mathrm{Q}_{10}\left(\mathrm{CoQ}_{10}\right)$ is an antioxidant and improves endothelial function in some subjects at risk of $\mathrm{CVD}^{(24)}$. Chai et $a{ }^{(25)}$ investigated the association of circulating $\operatorname{CoQ}_{10}$ levels with PCa risk. They concluded that moderate levels of circulating $\mathrm{CoQ}_{10}$ may reduce $\mathrm{PCa}$ risk; however, the findings did not reach statistical significance. Most preliminary studies with $n-3, n-6$ and $\mathrm{CoQ}_{10}$ have been investigative and suggested conflicting results regarding clinical efficacy in patients with $\mathrm{PCa}$, without addressing the effects of specific PUFA and $\mathrm{COQ}_{10}$ on serum PSA levels separately ${ }^{(22,23,25,26)}$. Therefore, we need further rigorous randomised studies.

\section{Materials and methods}

\section{Study subjects}

Recruitment and data collection were performed between July 2009 and November 2010. A total of 600 healthy men aged 40-70 years were recruited via local advertisements for a study of PCa. They were judged to be in good health based on a complete physical examination, medical and surgical history, electrocardiogram and laboratory tests, including serum biochemistry, haematology and urinalysis. None of the participants had lower urinary tract symptoms, a history of systemic inflammatory illness or urogenital disorders. The present study was conducted according to the guidelines laid down in the Declaration of Helsinki, and all procedures involving human subjects/patients were approved by the Medical Ethics Committee at the site. Verbal consent was witnessed and formally recorded.

\section{Inclusion/exclusion criteria}

The inclusion criteria were age between 40 and 70 years and no drug or alcohol dependence. Exclusion criteria included age ( $<40$ or $>70$ years); inability or reluctance to comply with study treatment; disease or medication that might interfere with the metabolism of PUFA or CoQ 10 , including diabetes mellitus and vitamin $\mathrm{E}$ consumption; significant liver (total bilirubin $>2 \mathrm{mg} / 100 \mathrm{ml}$ ) and renal (serum creatinine $>2 \mathrm{mg} / 100 \mathrm{ml}$ ) function impairments; history of a cardiovascular event; hypertension (resting blood pressure $>140 \mathrm{mmHg}$ systolic and/or $>90 \mathrm{mmHg}$ diastolic); history of pancreatitis; and the use of fish oil capsules or other $n-3, n-6$ PUFA or $\mathrm{CoQ}_{10}$ supplements within 6 months of the study. Men with baseline abnormal digital rectal examination or transrectal ultrasonography and serum total PSA level $>2.5 \mathrm{ng} / \mathrm{ml}$ were excluded from the study and referred for further investigations.

\section{Evaluations}

All participants underwent complete physical examination and digital rectal examination. The following data were collected from each participant: medical and surgical history, occupational status and educational level, smoking history, height and weight and family history of PCa. The study consisted of five clinic visits: one screening visit, one visit during the baseline period and three visits during double-blind treatment. At screening (week - 8), patients meeting the initial eligibility criteria received detailed explanation regarding study protocol and purposes. Participation was voluntary throughout the study period and subjects were given the opportunity to withdraw at any time they desired. Serum PSA was measured three times at 1 -week intervals at baseline (at weeks $-4,-3$ and -2 ).

Each visit was preceded by a $12 \mathrm{~h}$ fasting, and blood samples were taken for complete blood count, measurement of serum total PSA, TAG, lipid profiles (total cholesterol, LDL and HDL), serum levels of testosterone, dihydrotestosterone (DHT), luteinising hormone (LH) and sex hormone-binding globulin (SHBG) and biochemical safety measures (liver function tests). All men were requested to abstain from sexual activity for at least $24 \mathrm{~h}$ prior to blood sampling. Serum PSA levels were measured by a dissociation-enhanced lanthanide fluorescent immunoassay (DELFIA) PSA dual-label free/total PSA kit (Wallac Oy). The detection sensitivity for PSA was $0.05 \mathrm{ng} / \mathrm{ml}(5 \% \quad \mathrm{CV}$ at $2 \cdot 3 \mathrm{ng} / \mathrm{ml})$. Prostate volume was measured by using transrectal ultrasonography. At each follow-up visit (weeks 4, 8 and 12), serum levels of PSA were assessed two times.

Serum fatty acid composition was measured by using GC, as described previously ${ }^{(27)}$, and expressed as concentrations ( $\mu \mathrm{g} / \mathrm{l}$ or $\mu \mathrm{mol} / \mathrm{l})$. CV were $3.5 \%$ for EPA, $3 \cdot 1 \%$ for DHA and $3 \cdot 2 \%$ for GLA. Blood samples were analysed for total $\mathrm{CoQ}_{10}$ by HPLC using the methodology adapted from that of Tang et $a{ }^{(28)}$. CV for total $\mathrm{CoQ}_{10}$ quantification was $3.3 \%$.

Because plasma volume and body surface area influence PSA concentrations significantly ${ }^{(29)}$, we calculated body surface area and plasma volume using the following formulas for putting them in multivariate logistic regression analysis:

$$
\text { Body surface area } \begin{aligned}
\left(\mathrm{m}^{2}\right)= & \text { body weight }(\mathrm{kg})^{0.425} \\
& \times \text { height }(\mathrm{m})^{0.725} \times 0.2025,
\end{aligned}
$$

Plasma volume $($ litres $)=$ body surface area $\left(\mathrm{m}^{2}\right) \times 1 \cdot 670$.

Of recruited subjects, 504 met study eligibility and consented to proceed with the study protocol.

\section{Randomisation procedure}

Included participants were randomly assigned 1:1 to $n$-3 fatty acids $(1.12 \mathrm{~g}$ of EPA and $0.72 \mathrm{~g}$ of DHA per capsule; EPAX 5500TG, EPAX AS) (group 1, n 126), n-6 fatty acid (600 mg GLA per capsule; Vitex Pharmaceuticals Pty Ltd) (group 2, $n$ 126), $\mathrm{CoQ}_{10}$ (100 mg per capsule; Nutri $\mathrm{Q}_{10}$, Nutri Century) (group 3, $n$ 126) or a similar regimen of placebo (group 4 , $n$ 126) for 12 weeks. The placebo was maize oil, selected as it minimally affects the fatty acid content of the typical diet. The maize oil placebo contained 56\% linoleic acid, 28\% oleic acid, $12 \%$ palmitic acid and $4 \%$ of other fatty acids. Study medication was administered as two capsules to be taken twice daily. Patients were asked to maintain a stable, dietitian-advised, low-cholesterol diet for the whole duration of the trial. Adherence to dietary instructions was reinforced at each follow-up clinic visit. No other medication (herbal, synthetic or dietary supplementation) was allowed during 
the study period. Bottles of identical-appearing medication for each treatment group were set by an independent pharmacist and were assigned a participant number, which was provided by an independent statistician. Investigators, all study personnel, as well as the participants themselves were blinded to the randomisation table, the procedure and the code assignments.

During the 12-week, double-blind treatment phase, patients attended clinic visits at weeks 4, 8 and 12. At every clinic visit, patients were asked to report any possible adverse events or unusual symptoms. Compliance was checked in two ways. First, a capsule-dispensing record was completed and the information was coupled with unused capsule counts. In addition, plasma levels of EPA, DHA, GLA and $\mathrm{COQ}_{10}$ were measured at baseline ( -2 weeks) and at weeks 4,8 and 12 during the treatment period.

\section{End points}

The primary end point was percentage change from baseline in mean serum PSA levels at 12 weeks. Secondary end points included changes in fasting serum DHA, EPA, GLA, CoQ 10 , testosterone, DHT, LH and SHBG levels.

\section{Statistical analysis}

Data are expressed as means and standard deviations. The sample size was determined by using an effect size of 0.5 in a one-way ANOVA to give a power of 0.90 with a two-sided $\alpha$ of $0 \cdot 01$. Assuming a potential dropout rate of $20 \%$, a final sample size of 120 subjects was randomly assigned to each of four study groups ( $n$ 480). Because of the exponential distribution of PSA concentrations, serum PSA values were reported as the geometric mean. Student's $t$ - or Mann-Whitney's tests were applied for continuous variables. $\chi^{2}$ or Fisher exact tests were used for categorical data. After testing data for normality (Kolmogorov-Smirnov statistic with Lillefors correction), Student's paired $t$ or Wilcoxon signed-rank test was used to compare values between baseline and treatment at 12 weeks. We used Kruskal-Wallis one-way ANOVA or ANOVA on ranks to compare baseline or treatment effects among study groups. Statistical significance between two groups was examined by unpaired Student's $t$ test. Statistical significance between more than two groups was assessed by one-way ANOVA. A list-wise deletion approach was used to handle missing data, therefore, excluding participants who missed one or two follow-up visits ${ }^{(30)}$. OR and 95\% CI were computed in the multivariable logistic regression model. We put demographic (age, body surface area, plasma volume, prostate volume, occupational status, educational level and smoking status) and clinical (serum testosterone, DHT, LH, TAG, cholesterol, LDL and HDL) covariates into the multivariable logistic regression model. To assess the correlations between serum PSA levels and the continuous and categorical predictor variables, Spearman's correlation coefficient and $\chi^{2}$ tests were used, respectively. Two-tailed $P<0.05$ was considered statistically significant. The statistical analysis was carried out by SPSS version 18.0 for Windows (SPSS Inc.).

\section{Results}

\section{Characteristics of the participants}

Table 1 demonstrates demographic and clinical characteristics of study participants. Baseline characteristics of randomised subjects revealed no statistically significant differences between the four groups. A total of 600 subjects were screened for eligibility, with 504 subjects $(84.0 \%)$ being randomised (126 in each group). Of 504 randomised subjects, seventy-five dropped out of the study. Study withdrawal and absenteeism resulted in 429 subjects completing the whole study period. Overall, the mean age of participants was $52 \cdot 1$ (SD 6.2) years. According to the FFQ completed by the study subjects before and after the study, intake of $n-3, n-6$ and $\mathrm{CoQ}_{10}$ from foods did not change significantly in the intervention or placebo groups during the study.

\section{Primary end point}

In Table 2, the effects of the intervention on serum levels of PSA are demonstrated. Placebo treatment non-significantly reduced serum PSA level by $2 \cdot 3$ (95\% CI $1.9,2 \cdot 7) \%$. For simplicity, we refer to the supplements by the major fatty acid names, namely EPA for $n$-3 fatty acids and GLA for $n-6$ fatty acid. EPA treatment significantly reduced serum PSA level by 30.0 (95\% CI 25, 36)\% ( $P=0.004)$ from baseline. In contrast, GLA therapy significantly increased serum PSA concentration by 15.0 (95\% CI 11,20$) \%(P=0.02)$. CoQ 10 therapy also significantly reduced serum PSA level by $33 \cdot 0$ (95\% CI 27, 40)\% (P=0.002). The magnitude of decrease in serum PSA levels was significantly different when results from EPA and $\mathrm{CoQ}_{10}$ therapy were compared, despite both therapies resulting in a comparable decrease in serum PSA levels ( $P=0.01$ by ANOVA). Geometric means ( $95 \% \mathrm{CI}$ ) of serum levels of PSA in the intervention and placebo groups are shown in Table 2 .

\section{Secondary end points}

In the intervention group, serum levels of DHA increased by $93(95 \%$ CI 84,104$) \%(P=0.0001)$, EPA by $144(95 \% \mathrm{CI}$ $125,172) \%(P=0 \cdot 0001)$, GLA by $140(95 \%$ CI 126,177$) \%$ $(P=0.0001)$ and $\mathrm{CoQ}_{10}$ by $91(95 \% \mathrm{CI} 84,99) \%(P=0.0001)$, whereas DHA and EPA showed a significant decrease by 28 $(95 \%$ CI 22, 35)\% $(P=0.02)$ and $17(95 \%$ CI 14,21$) \%$ $(P=0.03)$, respectively, in subjects who took GLA. In contrast, in the placebo group, none of the serum levels of DHA, EPA, GLA and $\mathrm{COQ}_{10}$ changed significantly during the study period. Serum levels of LH, SHBG, testosterone and DHT before and after the intervention are demonstrated in Table 3. In the intervention groups and placebo group, changes in plasma levels of these hormones did not reach statistical significance (for details, see Table 3).

\section{Secondary analysis}

As expected, serum PSA levels were significantly correlated with age $(r 0.48 ; 95 \%$ CI $0.25,0.67 ; P=0.001)$. To confirm 
Table 1. Frequency distributions of selected variables for cases and controls

(Mean values and standard deviations; number of participants and percentages)

\begin{tabular}{|c|c|c|c|c|c|c|c|c|}
\hline \multirow[b]{2}{*}{ Variables } & \multicolumn{2}{|c|}{$n-3(n$ 126) } & \multicolumn{2}{|c|}{$n-6(n 126)$} & \multicolumn{2}{|c|}{$\mathrm{CoQ}_{10}(n 126)$} & \multicolumn{2}{|c|}{ Placebo $(n 126)$} \\
\hline & Mean & SD & Mean & SD & Mean & SD & Mean & SD \\
\hline Age (years) & $51 \cdot 8$ & $6 \cdot 6$ & $52 \cdot 4$ & $6 \cdot 4$ & $52 \cdot 7$ & $6 \cdot 1$ & $52 \cdot 2$ & $6 \cdot 2$ \\
\hline \multicolumn{9}{|l|}{ Serum hormones } \\
\hline Testosterone (nmol/l) & $17 \cdot 6$ & 3.8 & $17 \cdot 7$ & 3.9 & $17 \cdot 3$ & $3 \cdot 2$ & $17 \cdot 2$ & 3.7 \\
\hline Dihydrotestosterone (nmol/l) & 1.4 & 0.4 & 1.5 & 0.4 & 1.5 & 0.3 & 1.5 & 0.4 \\
\hline $\mathrm{LH}(\mathrm{IU} / \mathrm{I})$ & $9 \cdot 2$ & 3.0 & $9 \cdot 1$ & 3.0 & 9.6 & $3 \cdot 2$ & $9 \cdot 6$ & 3.1 \\
\hline FSH (IU/l) & $7 \cdot 4$ & $2 \cdot 4$ & $7 \cdot 6$ & $2 \cdot 2$ & 7.5 & $2 \cdot 0$ & $7 \cdot 6$ & $2 \cdot 1$ \\
\hline TSH (mlU/ml) & $2 \cdot 2$ & 1.2 & $2 \cdot 1$ & $1 \cdot 2$ & $2 \cdot 1$ & $1 \cdot 2$ & $2 \cdot 2$ & 1.2 \\
\hline SHBG $(\mathrm{nmol} / \mathrm{l})$ & 47 & 7 & 46 & 7 & 49 & 7 & 48 & 7 \\
\hline \multicolumn{9}{|l|}{ Lipid profile (mg/100 ml) } \\
\hline Total cholesterol & 161.4 & $33 \cdot 2$ & $157 \cdot 7$ & 31.6 & $158 \cdot 1$ & 34.6 & $159 \cdot 7$ & 33.4 \\
\hline TAG & $156 \cdot 4$ & 28.4 & $152 \cdot 4$ & $30 \cdot 8$ & $150 \cdot 4$ & $32 \cdot 2$ & 157.4 & $31 \cdot 2$ \\
\hline LDL & $135 \cdot 1$ & $19 \cdot 4$ & 133.4 & $32 \cdot 1$ & $138 \cdot 1$ & $21 \cdot 8$ & 131.4 & 30.6 \\
\hline $\mathrm{HDL}$ & 41.2 & $7 \cdot 4$ & $45 \cdot 2$ & $8 \cdot 2$ & $43 \cdot 2$ & $8 \cdot 1$ & $42 \cdot 2$ & $7 \cdot 7$ \\
\hline \multicolumn{9}{|l|}{ Prostate volume $\left(\mathrm{cm}^{3}\right)$} \\
\hline Transition zone & $29 \cdot 1$ & $4 \cdot 2$ & $28 \cdot 7$ & $4 \cdot 3$ & 28.8 & 4.0 & $28 \cdot 6$ & $4 \cdot 1$ \\
\hline \multirow[t]{2}{*}{ Prostate gland } & $39 \cdot 2$ & $12 \cdot 4$ & $39 \cdot 1$ & $12 \cdot 1$ & 38.9 & $12 \cdot 2$ & 39.4 & $12 \cdot 1$ \\
\hline & $n$ & $\%$ & $n$ & $\%$ & $n$ & $\%$ & $n$ & $\%$ \\
\hline \multicolumn{9}{|l|}{ Occupational status } \\
\hline Employed & 66 & $52 \cdot 4$ & 64 & $50 \cdot 8$ & 67 & $53 \cdot 2$ & 65 & 51.6 \\
\hline Unemployed & 22 & $17 \cdot 5$ & 21 & $16 \cdot 7$ & 23 & $18 \cdot 2$ & 24 & $19 \cdot 0$ \\
\hline Retired & 38 & $30 \cdot 1$ & 41 & 32.5 & 36 & $28 \cdot 6$ & 37 & 29.4 \\
\hline \multicolumn{9}{|l|}{ Smoking status } \\
\hline Never & 40 & 31.8 & 42 & 33.3 & 39 & 30.9 & 41 & 32.5 \\
\hline Former & 30 & $23 \cdot 8$ & 31 & $24 \cdot 6$ & 32 & $25 \cdot 4$ & 31 & 24.6 \\
\hline Current & 56 & 44.4 & 53 & $42 \cdot 1$ & 55 & $43 \cdot 7$ & 54 & $42 \cdot 9$ \\
\hline \multicolumn{9}{|l|}{ Education level } \\
\hline None & 0 & & 0 & & 0 & & 0 & \\
\hline Primary school & 47 & $37 \cdot 3$ & 48 & $38 \cdot 1$ & 46 & $36 \cdot 5$ & 45 & 35.7 \\
\hline High school & 75 & 59.5 & 76 & $60 \cdot 3$ & 76 & $60 \cdot 3$ & 77 & $61 \cdot 1$ \\
\hline Graduate & 4 & $3 \cdot 2$ & 2 & 1.6 & 4 & $3 \cdot 2$ & 4 & 3.2 \\
\hline \multicolumn{9}{|l|}{ BMI category $\left(\mathrm{kg} / \mathrm{m}^{2}\right)$} \\
\hline Normal (18.5-24.9) & 33 & $26 \cdot 2$ & 31 & $24 \cdot 6$ & 34 & $27 \cdot 0$ & 32 & $25 \cdot 4$ \\
\hline Overweight (25.0-29.9) & 64 & $50 \cdot 8$ & 66 & $52 \cdot 4$ & 62 & $49 \cdot 2$ & 61 & 48.4 \\
\hline Obese $(30 \cdot 0-34.9)$ & 24 & $19 \cdot 0$ & 25 & $19 \cdot 8$ & 26 & $20 \cdot 6$ & 28 & $22 \cdot 2$ \\
\hline Morbidly obese $(\geq 35.0)$ & 5 & 4.0 & 4 & $3 \cdot 2$ & 4 & $3 \cdot 2$ & 5 & 4.0 \\
\hline \multicolumn{9}{|l|}{ Age distribution (years) } \\
\hline$\leq 50$ & 33 & $26 \cdot 2$ & 35 & $27 \cdot 8$ & 31 & 24.6 & 34 & $27 \cdot 0$ \\
\hline $51-60$ & 52 & 41.3 & 54 & $42 \cdot 8$ & 50 & $39 \cdot 7$ & 53 & $42 \cdot 1$ \\
\hline $61-70$ & 41 & 32.5 & 37 & $29 \cdot 4$ & 45 & $35 \cdot 7$ & 39 & 30.9 \\
\hline
\end{tabular}

whether multivariate analyses required adjustment for a dose-response, the recorded values of PSA, BMI, plasma volume, age, smoking history, prostate volume and duration of therapy coded as a continuous variable in months were analysed. The multivariable analysis of PSA demonstrated that serum values of PSA were strongly correlated with duration of EPA $(r-0.62 ; 95 \% \mathrm{CI}-0.42,-0.77 ; P=0.003)$, GLA $(r \quad 0.42 ; 95 \%$ CI $0.31,0.58 ; P=0.02)$ and $\mathrm{CoQ}_{10}$ use $(r-0.77 ; 95 \%$ CI $-0.56,-0.87 ; P=0.001)$. There were also significant correlations between serum values of DHA, EPA, GLA and $\mathrm{COQ}_{10}$ and serum PSA levels. No significant correlation existed between serum PSA concentrations and testosterone $(r 0.24 ; 95 \% \mathrm{CI}-0.031,0.48 ; P=0.24)$, DHT $(r 0.31 ; 95 \% \mathrm{CI}-0.032,0.54 ; P=0.62), \mathrm{LH}(r 0.18 ; 95 \% \mathrm{CI}$ $-0.032,0.37 ; P=0.44)$ and SHBG levels ( $r 0.17 ; 95 \% \mathrm{CI}$ $-0.032,0 \cdot 48 ; P=0 \cdot 49)$.

\section{Discussion}

The present prospective randomised study concluded that men aged 40-70 years, who were administered EPA and $\mathrm{CoQ}_{10}$, had lower serum PSA levels. After adjusting for significant covariates, such as age, plasma volume, BMI and prostate volume, the significance of findings remained unchanged. An effect of PUFA and $\mathrm{COQ}_{10}$ on serum PSA levels could potentially complicate PCa detection. Men who would be more affected by an unpredicted serum PSA decrease or rise are those with serum PSA concentrations near a cut-off value for which prostate biopsy is indicated. Due to ethical reasons, we only recruited men with serum levels of PSA $<2.5 \mathrm{ng} / \mathrm{ml}$. There are a few well-documented risk factors for $\mathrm{PCa}$, including family history, some specific genetic variants and being of African-American descent ${ }^{(31,32)}$. However, a large number of men with PCa do not carry these 
risk factors, suggesting the presence of some unexplained components in the pathogenesis of PCa. Diet is one of the potential environmental risk factors for developing $\mathrm{PCa}^{(33)}$. Over the past two decades, epidemiological studies have addressed the impact of dietary fat on PCa risk ${ }^{(34)}$. However, the actual mechanistic role of dietary fat in PCa has remained unknown. Immigrants from Poland and Japan to the USA demonstrate a significant rise in the risk of developing clinical $\mathrm{PCa}$, comparable with the US population ${ }^{(14)}$. These findings underscore environmental factors, and possibly diet, as significant potential contributing factors. $n-3$ and $n-6$ PUFA are among commonly used supplements and may have some effects on prostate biology. Results of studies investigating the effect of $n-3$ PUFA use on PCa are conflicting. In seven prospective studies, the issue of fish intake and PCa risk have been investigated. Of these studies, three of them reported that high intake of fish might reduce the risk of $\mathrm{PCa}^{(35-37)}$, one reported a positive association ${ }^{(38)}$, while three others had conflicting results ${ }^{(39-41)}$. We are not aware of other publications directly reporting on the association between EPA, GLA and $\mathrm{CoQ}_{10}$ use and serum PSA levels. However, several observational studies have suggested that $n-3$ and $n-6$ PUFA or $\mathrm{CoQ}_{10}$ may have a role in the pathogenesis of PCa. Berquin et al. ${ }^{(15)}$ investigated the influence of fatty acids on PCa risk in animals. They found that $n-3$ PUFA decreased prostate tumour growth, delayed histopathological progression and increased survival, while n-6 PUFA had opposite effects. In another study, Kobayashi et al. ${ }^{(23)}$ examined whether changing the dietary content of $n-3$ and $n$-6 PUFA alters the growth of androgen-sensitive PCa xenografts. They found that tumour growth rates, final tumour volumes and serum PSA levels were decreased in the $n-3$ group compared with the $n-6$ group. Friedrichs et al..$^{(42)}$ reported that DHA and EPA are able to prevent progression of LNCaP cells, whereas arachidonic acid ( $n-6$ fatty acid) actually accelerated cell growth. This is in line with the present findings. In the present study, GLA ( $n-6$ fatty acid) administration resulted in increased serum PSA level by $15 \%$. In another study, Akinsete et al. ${ }^{(21)}$ investigated whether changing from a diet that approximates $n-6$ fat content of the Western diet to a high- $n-3$ fat diet might decrease PCa risk in mice. They concluded that consumption of a high- $n-3$ diet slows down prostate tumorigenesis through decreasing oestradiol and testosterone levels. However, in the present study, serum concentration of testosterone did not alter significantly by EPA administration. In addition, serum PSA levels did not have significant correlations with serum testosterone levels. Also, in a study by Giltay et $a l^{(43)}, n-3$ fatty acid supplementation did not affect serum total testosterone levels.

The possible mechanism through which the $n-3$ PUFA exert their anti-tumour effect is by the anti-inflammatory effects of PUFA, through mediation of cyclo-oxygenase ${ }^{(44)}$. Cyclo-oxygenase is a key enzyme in fatty acid metabolism and inflammation ${ }^{(44)}$. Fradet et al. ${ }^{(45)}$ reported that $n$-3 PUFA affect prostate inflammation and carcinogenesis through the cyclo-oxygenase-2 enzymatic pathway. This potential protective effect may be altered by genetic variants in cyclooxygenase- $2^{(44)}$. Another mechanism is by the suppression 
Table 3. Serum concentrations of testosterone (T), dihydrotestosterone (DHT), luteinising hormone (LH) and sex hormone-binding globulin (SHBG) in study groups before and after intervention (Mean values and $95 \%$ confidence intervals)

\begin{tabular}{|c|c|c|c|c|c|c|c|c|}
\hline \multirow[b]{2}{*}{ Serum } & \multirow[b]{2}{*}{ Group } & \multicolumn{2}{|c|}{ Before treatment } & \multicolumn{2}{|c|}{ After treatment } & \multicolumn{2}{|c|}{$\%$ Change } & \multirow[b]{2}{*}{$P^{*}$} \\
\hline & & Mean & $95 \% \mathrm{Cl}$ & Mean & $95 \% \mathrm{Cl}$ & Mean & $95 \% \mathrm{Cl}$ & \\
\hline \multirow{4}{*}{$\mathrm{T}(\mathrm{nmol} / \mathrm{l})$} & Placebo & $17 \cdot 2$ & $13 \cdot 4,20 \cdot 6$ & $17 \cdot 8$ & $13 \cdot 9,21 \cdot 3$ & 3 & 1,5 & NA \\
\hline & $n-3$ & $17 \cdot 6$ & $13 \cdot 7,21 \cdot 1$ & $17 \cdot 2$ & $13 \cdot 1,20 \cdot 2$ & -2 & $-5,-1$ & 0.41 \\
\hline & $n-6$ & $17 \cdot 7$ & $13 \cdot 3,21 \cdot 5$ & $18 \cdot 2$ & $13 \cdot 8,22 \cdot 2$ & 3 & 1,5 & 0.92 \\
\hline & CoQ10 & $17 \cdot 3$ & $13 \cdot 1,20 \cdot 3$ & $18 \cdot 8$ & $14 \cdot 4,22 \cdot 7$ & 9 & 6,12 & 0.35 \\
\hline \multirow[t]{4}{*}{ DHT (nmol/l) } & Placebo & 1.5 & $1 \cdot 2,1 \cdot 9$ & 1.7 & $1 \cdot 3,2 \cdot 1$ & 13 & 10,17 & NA \\
\hline & $n-3$ & 1.4 & $1 \cdot 1,1 \cdot 8$ & 1.5 & $1 \cdot 2,1 \cdot 8$ & 7 & 5,8 & 0.41 \\
\hline & $n-6$ & 1.5 & $1.1,1.9$ & 1.4 & $1 \cdot 1,1 \cdot 7$ & -6 & $-9,-4$ & 0.07 \\
\hline & CoQ10 & 1.5 & $1 \cdot 2,1 \cdot 8$ & $1 \cdot 8$ & $1 \cdot 3,2 \cdot 2$ & 20 & 16,25 & 0.32 \\
\hline \multirow[t]{4}{*}{ LH (IU/I) } & Placebo & $9 \cdot 6$ & $6 \cdot 4,12 \cdot 8$ & 9.2 & $6 \cdot 1,12 \cdot 3$ & -4 & $7,-2$ & NA \\
\hline & $n-3$ & 9.2 & $6 \cdot 1,12 \cdot 2$ & $9 \cdot 6$ & $6 \cdot 1,12 \cdot 2$ & 4 & 3,6 & 0.22 \\
\hline & $n-6$ & $9 \cdot 1$ & $6 \cdot 0,12 \cdot 0$ & $8 \cdot 6$ & $5 \cdot 8,11 \cdot 8$ & -5 & $-8,-3$ & 0.82 \\
\hline & CoQ10 & $9 \cdot 6$ & $6 \cdot 2,12 \cdot 7$ & $9 \cdot 1$ & $6 \cdot 0,12 \cdot 1$ & -5 & $-8,-4$ & 0.81 \\
\hline \multirow[t]{4}{*}{$\mathrm{SHBG}(\mathrm{nmol} / \mathrm{l})$} & Placebo & 48 & 41,55 & 52 & 43,58 & 8 & 5,12 & NA \\
\hline & $n-3$ & 47 & 40,53 & 44 & 37,51 & -6 & $-10,-4$ & 0.24 \\
\hline & $n-6$ & 46 & 38,51 & 49 & 42,58 & 6 & 3, 8 & 0.75 \\
\hline & CoQ10 & 49 & 42,57 & 45 & 38,52 & -8 & $-12,-7$ & 0.36 \\
\hline
\end{tabular}

$\mathrm{NA}$, not available; $\mathrm{CoQ}_{10}$, coenzyme $\mathrm{Q}_{10}$.

${ }^{*} P$ values refer to the difference in change compared with placebo. All $P$ values are from two-sided $\chi^{2}$ tests.

of mammalian target of rapamycin (mTOR) signalling and androgen receptor expression ${ }^{(42)}$.

$\mathrm{CoQ}_{10}$ is considered an important cellular antioxidant and a potential anticancer agent ${ }^{(46)}$. In addition to its role as an antioxidant, other roles include a non-specific stimulant for the immune system ${ }^{(47)}$ and a role in membrane stabilisation, inhibition of intracellular phospholipases and stabilisation of Ca-dependent slow channels ${ }^{(48)}$. Very few studies have addressed the role of $\mathrm{CoQ}_{10}$ on PCa and serum PSA levels, with contradicting results. Two preliminary studies with $\mathrm{CoQ}_{10}$ have demonstrated potential clinical benefits in $\mathrm{PCa}$ patients ${ }^{(49,50)}$. On the other hand, Chai et al. ${ }^{(25)}$ examined the association of serum $\mathrm{CoQ}_{10}$ levels with $\mathrm{PCa}$ risk in a case-control study. They did not find a statistically significant association between plasma $\mathrm{CoQ}_{10}$ levels and PCa risk. In another study, Hoenjet et $a l .{ }^{(26)}$ assessed the effect of a nutritional supplement containing vitamin $\mathrm{E}$, Se, vitamin $\mathrm{C}$ and $\mathrm{COQ}_{10}$ on serum PSA levels in patients with hormonally untreated PCa and increasing serum PSA levels. The supplementation did not affect serum level of PSA.

The results from the present study suggest that men on EPA and $\mathrm{CoQ}_{10}$ supplementation may require a lower threshold (about 30\%) for PSA screening. However, these findings need to be interpreted with caution. The present study was not without limitation. The main limitation is that the men with PSA levels $>2.5 \mathrm{ng} / \mathrm{ml}$ were excluded from the study. Currently, the standard cut-off of $4 \mathrm{ng} / \mathrm{ml}$ is still considered preferable for men aged between 50 and 70 years. As this is often used as a critical or focal point, exclusion of those patients with total PSA at $2 \cdot 5-10 \mathrm{ng} / \mathrm{ml}$ is questioned. Furthermore, while $2 \mathrm{ng} / \mathrm{ml}$ may be normal in a 60 -year-old man, that level is more likely to signify cancer in men aged 40-49 years. Thus, addressing the issue of whether fatty acids influence normal PSA levels (with a cancer risk of $1 \%$ ) does not appear to be as an important issue as whether those men with PSA of $4-10 \mathrm{ng} / \mathrm{ml}$, who are at a greater risk for PCa, will have PSA levels altered by fatty acids. The present study is a preliminary one, and further studies with different design are needed to draw final conclusions. Another study limitation is that, although we demonstrated a PSA decrease, actually we did not demonstrate that this decrease in PSA delays PCa diagnosis or it results in a decrease in risk of PCa. In addition, although statistically PSA was altered with the duration of treatment, longer studies are necessary to reach an appropriate conclusion. Also, studies need to be carried out to determine whether removal of the treatment allows the PSA values to return back to pre-treatment levels. PSA velocity may be an important tool for assessment. Study strengths include a reasonable sample size, prospective randomised design and the ability to control for a variety of variables.

\section{Conclusion}

In conclusion, EPA and $\mathrm{CoQ}_{10}$ use are associated with decreased serum levels of PSA. It may be necessary to establish a different PSA cut-off value for men on these supplements. These findings may have possible clinical implications. Dietary supplements containing $n-3$ PUFA or $\mathrm{CoQ}_{10}$ may have a protective effect against developing PCa and/or a therapeutic effect in men with PCa.

\section{Acknowledgements}

We thank the many clinicians who endorsed the study and all patients and control individuals who participated in the study, without whom the present study would not be possible. We are grateful to Saba Safarinejad for statistical analyses. We have no disclosures to report. We have no conflict of interest, whether of a financial or other nature. We did not make any financial arrangement with a company. We have 
no commercial affiliations to report. The authors' contributions are as follows: M. R. S. contributed to the conception and design, acquisition of data, analysis and interpretation of data, drafting the article, revising it for intellectual content and final approval of the completed article. N. S. contributed to the acquisition of data, drafting the article and the final approval of the completed article. S. S. contributed to the acquisition of data, analysis and interpretation of data and revising it for intellectual content.

\section{References}

1. Jemal A, Siegel R, Xu J, et al. (2010) Cancer statistics, 2010. CA Cancer J Clin 60, 277-300.

2. Centers for Disease Control and Prevention (2005) Prostate Cancer: The Public Health Perspective (Fact Sheet 2003). http://www.cdc.gov/cancer/prostate/prostate.htm

3. Jemal A, Murray T, Ward E, et al. (2005) Cancer statistics, 2005. CA Cancer J Clin 55, 10-30.

4. Etzioni RD, Howlader N, Shaw PA, et al. (2005) Long-term effects of finasteride on prostate specific antigen levels: results from the prostate cancer prevention trial. J Urol 174, 877-881.

5. Saraiya M, Kottiri BJ, Leadbetter S, et al. (2005) Total and percent free prostate-specific antigen levels among U.S. men, 2001-2002. Cancer Epidemiol Biomarkers Prev 14, $2178-2182$.

6. Catalona WJ, Partin AW, Slawin KM, et al. (2000) Percentage of free PSA in black versus white men for detection and staging of prostate cancer: a prospective multicenter clinical trial. Urology 55, 372-376.

7. Wallner LP, Morgenstern H, McGree ME, et al. (2011) The effects of type 2 diabetes and hypertension on changes in serum prostate specific antigen levels: results from the Olmsted County study. Urology 77, 137-141.

8. Sonn GA, Aronson W \& Litwin MS (2005) Impact of diet on prostate cancer: a review. Prostate Cancer Prostatic Dis $\mathbf{8}$, 304-310.

9. Açıkgöz Ş, Can M, Doğan SM, et al. (2011) Prostate specific antigen levels after acute myocardial infarction. Acta Biochim Pol 58, 541-545.

10. Grubb RL 3rd, Black A, Izmirlian G, et al. (2009) Serum prostate-specific antigen hemodilution among obese men undergoing screening in the Prostate, Lung, Colorectal, and Ovarian Cancer Screening Trial. Cancer Epidemiol Biomarkers Prev 18, 748-751.

11. Singer EA, Palapattu GS \& van Wijngaarden E (2008) Prostate-specific antigen levels in relation to consumption of nonsteroidal anti-inflammatory drugs and acetaminophen: results from the 2001-2002 National Health and Nutrition Examination Survey. Cancer 113, 2053-2057.

12. Krane LS, Kaul SA, Stricker HJ, et al. (2010) Men presenting for radical prostatectomy on preoperative statin therapy have reduced serum prostate specific antigen. J Urol 183, 118-124.

13. Jemal A, Bray F, Center MM, et al. (2011) Global cancer statistics. CA Cancer J Clin 61, 69-90.

14. Astorg P (2004) Dietary $n-6$ and $n$-3 polyunsaturated fatty acids and prostate cancer risk: a review of epidemiological and experimental evidence. Cancer Causes Control 15, 367-386.

15. Berquin IM, Min Y, Wu R, et al. (2007) Modulation of prostate cancer genetic risk by omega- 3 and omega- 6 fatty acids. J Clin Invest 117, 1866-1875.

16. Weaver KL, Ivester P, Seeds M, et al. (2009) Effect of dietary fatty acids on inflammatory gene expression in healthy humans. J Biol Chem 284, 15400-15407.
17. Simopoulos AP (2003) Importance of the ratio of omega-6/ omega-3 essential fatty acids: evolutionary aspects. World Rev Nutr Diet 92, 1-22

18. Sugano M \& Hirahara F (2000) Polyunsaturated fatty acids in the food chain in Japan. Am J Clin Nutr 71, 189S-96S.

19. Rose DP \& Connolly JM (1999) Omega-3 fatty acids as cancer chemopreventive agents. Pharmacol Ther 83, 217-244.

20. Connolly JM, Coleman M \& Rose DP (1997) Effects of dietary fatty acids on DU145 human prostate cancer cell growth in athymic nude mice. Nutr Cancer 29, 114-119.

21. Akinsete JA, Ion G, Witte TR, et al. (2012) Consumption of high $\omega-3$ fatty acid diet suppressed prostate tumorigenesis in C3(1) Tag mice. Carcinogenesis 33, 140-148.

22. Kelavkar UP, Hutzley J, Dhir R, et al. (2006) Prostate tumor growth and recurrence can be modulated by the omega6:omega-3 ratio in diet: athymic mouse xenograft model simulating radical prostatectomy. Neoplasia $\mathbf{8}, 112-124$.

23. Kobayashi N, Barnard RJ, Henning SM, et al. (2006) Effect of altering dietary omega-6/omega-3 fatty acid ratios on prostate cancer membrane composition, cyclooxygenase-2, and prostaglandin E2. Clin Cancer Res 12, 4662-4670.

24. Watts GF, Playford DA, Croft KD, et al. (2002) Coenzyme $\mathrm{Q}(10)$ improves endothelial dysfunction of the brachial artery in type II diabetes mellitus. Diabetologia 45, 420-426.

25. Chai W, Cooney RV, Franke AA, et al. (2011) Plasma coenzyme Q10 levels and prostate cancer risk: the multiethnic cohort study. Cancer Epidemiol Biomarkers Prev 20, $708-710$.

26. Hoenjet KM, Dagnelie PC, Delaere KP, et al. (2005) Effect of a nutritional supplement containing vitamin E, selenium, vitamin $\mathrm{c}$ and coenzyme Q10 on serum PSA in patients with hormonally untreated carcinoma of the prostate: a randomised placebo-controlled study. Eur Urol 47, 433-439.

27. Harris JI, Hibbeln JR, Mackey RH, et al. (2004) Statin treatment alters serum $n-3$ and $n-6$ fatty acids in hypercholesterolemic patients. Prostaglandins Leukot Essent Fatty Acids $\mathbf{7 1}$, 263-269.

28. Tang PH, Miles MV, DeGrauw A, et al. (2001) HPLC analysis of reduced and oxidized coenzyme Q10 in human plasma. Clin Chem 47, 256-265.

29. Loeb S, Carter HB, Schaeffer EM, et al. (2009) Should prostate specific antigen be adjusted for body mass index? Data from the Baltimore Longitudinal Study of Aging. J Urol 182, 2646-2651.

30. Howell DC (2010) Fundamental Statistics for the Behavioral Sciences. Belmont, CA: Wadsworth Publishing Company.

31. Fowke JH, Signorello LB, Chang SS, et al. (2006) Effects of obesity and height on prostate-specific antigen (PSA) and percentage of free PSA levels among African-American and Caucasian men. Cancer 107, 2361-2367.

32. Safarinejad MR, Shafiei N \& Safarinejad S (2010) Relationship between three polymorphisms of methylenetetrahydrofolate reductase (MTHFR C677T, A1298C, and G1793A) gene and risk of prostate cancer: a case-control study. Prostate $\mathbf{7 0}$, $1645-1657$.

33. Simopoulos AP (1999) Essential fatty acids in health and chronic disease. Am J Clin Nutr 70, 3 Suppl., 560S-569S.

34. Kolonel LN (2001) Fat, meat, and prostate cancer. Epidemiol Rev 23, 72-81.

35. Augustsson K, Michaud DS, Rimm EB, et al. (2003) A prospective study of intake of fish and marine fatty acids and prostate cancer. Cancer Epidemiol Biomarkers Prev 12, 64-67.

36. Pham TM, Fujino Y, Kubo T, et al. (2009) Fish intake and the risk of fatal prostate cancer: findings from a cohort study in Japan. Public Health Nutr 12, 609-613. 
37. Terry P, Lichtenstein P, Feychting M, et al. (2001) Fatty fish consumption and risk of prostate cancer. Lancet 357 , $1764-1766$

38. Allen NE, Sauvaget C, Roddam AW, et al. (2004) A prospective study of diet and prostate cancer in Japanese men. Cancer Causes Control 15, 911-920.

39. Le Marchand L, Kolonel LN, Wilkens LR, et al. (1994) Animal fat consumption and prostate cancer: a prospective study in Hawaii. Epidemiology 5, 276-282.

40. Mills PK, Beeson WL, Phillips RL, et al. (1989) Cohort study of diet, lifestyle, and prostate cancer in Adventist men. Cancer 64, 598-604.

41. Park SY, Murphy SP, Wilkens LR, et al. (2007) Fat and meat intake and prostate cancer risk: the multiethnic cohort study. Int J Cancer 121, 1339-1345.

42. Friedrichs W, Ruparel SB, Marciniak RA, et al. (2011) Omega-3 fatty acid inhibition of prostate cancer progression to hormone independence is associated with suppression of mTOR signaling and androgen receptor expression. Nutr Cancer 63, 771-777.

43. Giltay EJ, Geleijnse JM, Heijboer AC, et al. (2012) No effects of $n$-3 fatty acid supplementation on serum total testosterone levels in older men: the Alpha Omega Trial. Int $J$ Androl 35, 680-687.

44. Reese AC, Fradet V \& Witte JS (2009) Omega-3 fatty acids, genetic variants in COX-2 and prostate cancer. $J$ Nutrigenet Nutrigenomics 2, 149-158.

45. Fradet V, Cheng I, Casey G, et al. (2009) Dietary omega-3 fatty acids, cyclooxygenase- 2 genetic variation, and aggressive prostate cancer risk. Clin Cancer Res 15, 2559-2566.

46. Crane FL (2001) Biochemical functions of coenzyme Q10. J Am Coll Nutr 20, 591-598.

47. Hattersley JG (1996) Coenzyme Q10 and cancer. J Orthomol Med 2, 111-112.

48. Pepping J (1999) Coenzyme Q10. Am J Health Syst Pharm 56, 519-521.

49. Schroder FH, Dijk MA, Blom JM, et al. (2000) Tertiary prevention of prostate cancer by dietary intervention: results of a randomised, double blind, placebo controlled, crossover study. Eur J Urol 37, 96.

50. Folkers K, Osterborg A, Nylander M, et al. (1997) Activities of vitamin Q10 in animal models and a serious deficiency in patients with cancer. Biochem Biophys Res Commun 234, 296-299. 